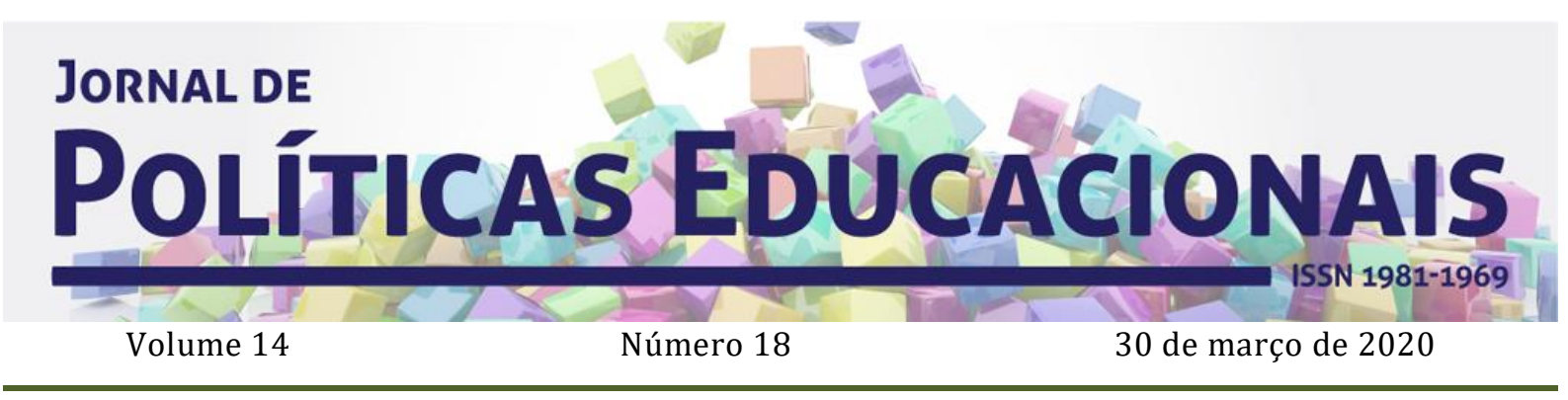

\title{
Egressos da EJA no ensino superior e a política de cotas da UERJ: entre desafios e potencialidades
}

\author{
EJA graduates in higher education and UERJ's quota policy: between \\ challenges and potentials.
}

\section{EJA egresses en educación superior y política de cuotas en UERJ: entre desafíos y potencialidad}

Marcia Soares de Alvarenga ${ }^{1}$ Cintya Roberta Santos ${ }^{2}$

Citação: ALVARENGA, M.S.; SANTOS, C. Egressos da EJA no ensino superior e a política de cotas da UERJ: entre desafios e potencialidades. Jornal de Políticas Educacionais. V. 14, n. 18. Março de 2020.

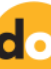

$\underline{\text { http://10.5380/ipe.v14i0.71460 }}$

Resumo: Produzido no contexto dos 10 anos de implantação da Política de Cotas para acesso aos cursos de graduação nas universidades estaduais do estado do Rio de Janeiro e nos 30 anos de promulgação da Constituição Brasileira, em 1988, o objetivo do artigo é analisar a inter-relação entre a modalidade da EJA e Política de Cotas na FFP/UERJ, tendo como recorte estudantes cotistas que ingressaram na UERJ no ano de 2016. A metodologia da pesquisa teve como ponto de partida dados colhidos em fontes institucionais através de sínteses cadastrais dos sistemas da universidade e questionário semiestruturados dirigidos para cotistas egressos da EJA. Os resultados da pesquisa indicam serem reduzidos os estudantes egressos da EJA que acessam a universidade pelo sistema de cotas, o que nos faz interpelar, dialeticamente, sobre os desafios enfrentados pelos dos estudantes egressos da EJA e a potência das cotas para a democratização da universidade.

Palavras-chave Egressos da EJA; Política de Cotas; Direito à Educação; Ensino Superior.

\begin{abstract}
Produced in the context of the 10 years of implementation of the Quota Policy for access to undergraduate courses at state universities in the State of Rio de Janeiro and in the 30 years of the promulgation of the Brazilian Constitution in 1988, the aim of the article is to analyze the interrelationship between the EJA (Education for Young Adults) Programme and the Quota Policy at FFP/UERJ, with the

\footnotetext{
${ }^{1}$ Doutora em Educação. Professora Associada da Universidade do Estado do Rio de Janeiro. Rio de Janeiro, RJ. Brasil. Orcid: https://orcid.org/0000-0002-8686-9844 E-mail: msalvarenga@uol.com.br

${ }^{2}$ Mestre em Educação. Assistente Social da Universidade Federal de Pernambuco. Recife, PE. Brasil. Orcid: https://orcid.org/0000-0001-8295-5975 E-mail: cintyaoliver@yahoo.com.br
} 
participation of quota students who joined UERJ in 2016. The research methodology was based on data collected from institutional sources through registration summaries of the university systems and semistructured questionnaires directed to, and filled in by, quota holders graduating from EJA. The outcomes of the research point out that the number of graduates from EJA who are admitted at university through the quota system is reduced, which makes us question, dialectically, about the challenges faced by the socioeconomic background of the graduates and the power of the quotas for the democratization of the university.

Keyword: EJA graduates; Quota Policy; Right to Education; Higher Education

Resumen: Producido en el contexto de los 10 años de implementación de la Política de Cuotas para el acceso a cursos de pregrado en universidades estatales en el estado de Río de Janeiro y en los 30 años de la promulgación de la Constitución brasileña en 1988, el objetivo del artículo es analizar la interrelación entre la modalidad de EJA y la Política de cuotas en FFP / UERJ, con la participación de estudiantes de cuotas que se unieron a UERJ en 2016. La metodología de investigación se basó en datos recopilados de fuentes institucionales a través de resúmenes catastrales de los sistemas universitarios y cuestionario semiestructurado para titulares de cuotas que se gradúen de EJA. Los resultados de la investigación indican que se reduce el número de estudiantes que se gradúan de la EJA que acceden a la universidad a través del sistema de cuotas, lo que nos hace cuestionar, dialécticamente, sobre los desafíos que enfrentan los estudiantes que se gradúan de la EJA y el poder de las cuotas para la democratización de la universidad.

Palabras clave: Egresados de la EJA; Política de Cuotas; Derecho a la educación; Enseñanza superior.

\section{Introdução}

Nos últimos trinta anos verificou-se, no Brasil, a expansão da escolarização em todas as etapas da escolarização da Educação Básica e do Ensino Superior. Em relação à primeira etapa, contudo, o prolongamento da obrigatoriedade escolar continua aberto às discussões e estudos sobre paradoxos produzidos na relação quantidade/qualidade ao combinar acesso à escola básica com desigualdades sociais.

Por sua vez, a demanda das camadas populares ao Ensino Superior ampliou os debates, dentro e fora do ambiente acadêmico, vindo a provocar o governo federal e governos estaduais a promoverem programas de incentivo para o ingresso a este nível de ensino. Na esfera federal, foram criados o FIES (Fundo de Financiamento Estudantil/ 1999), o ProUni (Programa Universidade Para Todos /2005), a UAB (Universidade Aberta do Brasil /2006), o REUNI (Programa de Apoio a Planos de Reestruturação e Expansão das Universidades Federais / 2007), o SISU (Sistema de Seleção Unificada / 2010) e a Lei de Cotas (Lei no 12.711/2012).

Em um contexto de expansão da escolarização, a Política de Cotas se insere em um ambiente de democratização do acesso à universidade pública. Na esfera federal, a Universidade de Brasília (UnB) implantou o sistema de cotas raciais, no ano de 2001, seguida pela Universidade Federal da Bahia (UFBA), no ano de 2003. Entre as universidades estaduais, destaca-se a Universidade do Estado do Rio de Janeiro (UERJ) por ter sido, junto com a Universidade Estadual do Norte Fluminense (UENF), a primeira 
universidade pública do Brasil a implantar sistema de cotas, em atendimento a um conjunto de Leis aprovadas pela Assembleia Legislativa do Estado do Rio de Janeiro (ALERJ), desde o ano de 2000 até o ano de 2018.

Neste período, foram crescentes o quantitativo de pesquisas realizadas sobre processos e implantação de sistemas de cotas, tanto de caráter comparativo (BEVILÁQUIA, 2005) quanto de estudos de casos (MOEHLECKE, 2002; FERES JÚNIOR E ZONINSEN, 2006; CERVI, 2014). Dentre os trabalhos publicados chama atenção o realizado por Heringer (2012), segundo o qual as políticas de permanência na educação superior e a ampliação de expectativas de estudantes do Ensino Médio (EM) continuam sendo os maiores desafios para estudantes egressos de escolas públicas, menor renda, pretos e pardos.

A par destes estudos, o presente artigo problematizou o acesso de egressos de estudantes da Educação de Jovens e Adultos (EJA) com enfoque nos estudantes cotistas que ingressaram na UERJ, no ano de 2016, pela Política de Cotas da universidade. A pesquisa teve por objetivo explorar um aspecto, ainda, ausente na literatura sobre o enlace entre a EJA e a Política de Cotas, analisando desafios e potencialidades em seus desdobramentos para as políticas públicas e, em última instância, para o direito à educação em todos os níveis e modalidades de ensino.

0 artigo está organizado em duas seções. Na primeira seção situamos a abordagem teórico-metodológica da pesquisa na qual tratamos os referenciais bibliográficos e os dados empíricos da pesquisa como relação entre linguagem e sociedade. Na segunda seção, apresentamos o contexto empírico da pesquisa, a Faculdade de Formação de Professores (FFP/UERJ), segunda maior unidade acadêmica da universidade e os dados da pesquisa. Nesta seção, cuidamos de identificar aspectos sensíveis ao objetivo do estudo.

Ao final, nas conclusões, expomos desafios e potencialidades que a pesquisa sugere para o campo das políticas públicas relativos ao enlace entre EJA e a Política de Cotas e suas ressonâncias para a democratização do acesso ao Ensino Superior, no atual quadro político brasileiro. 


\section{Abordagem teórico-metodológica da pesquisa}

No campo das ciências humanas, procedimentos de pesquisas que recorrem a questionários, entrevistas, relatórios, estudos demográficos, entre outros, buscam interrelacionar fontes de pesquisa para a produção de conhecimento sobre um recorte da realidade.

A EJA constitui um enclave dentro do EM, e, perceber os egressos dessa modalidade, que lograram entrar na UERJ pela Política de Cotas, muito pode nos dizer a respeito dos desafios e potencialidades desse enlace para a democratização do acesso à universidade pública dos setores populares apartados do direito à educação. Neste movimento de conhecer, encontramos nos fragmentos escritos por Bakhtin (2000) uma chave teórico-analítica para dialogar com as fontes bibliográficas e dados quantitativos, considerando-os materiais enunciativos, ou seja, expressões da linguagem humana dirigidas para outros em torno de um objeto de conhecimento.

No artigo, o interesse em interrogar sobre desafios e potencialidades de políticas públicas para acesso ao ensino superior foi desenhado por um conjunto de documentos que produzem sentidos sobre a relação entre EJA e Política de Cotas em suas repercussões sobre o ao ensino superior

O percurso polissêmico sobre estas políticas afirmativas de reparação têm sido realizado por vasta literatura dedicada às suas matrizes pretéritas e do presente cujos sentidos circulam em maior ou menor grau de inter-relacionamentos, e movimentam a corrente dialógica entre autores em suas problematizações informadas por diferentes perspectivas teórico-metodológicas.

Na profícua literatura que discute a EJA como questão política, social e cultural, se encontram estudos dedicados às análises sobre campanhas de alfabetização e em seus nexos com a Educação Popular (BEISEGEL, 1974; PAIVA, 1978, FÁVERO, 1983) com lentes voltadas para a relação entre o modelo econômico desenvolvimentista e regimes políticos que o sustentaram, seja em períodos democráticos, seja em períodos autoritários.

Em relação à literatura que contextualiza a EJA a partir do processo pós-transição democrática no Brasil, fontes mais recentes revelam que, sem tradição construída pela perspectiva das políticas públicas, a EJA é continuamente reiterada em sua posição de margem, em frágil vinculação com sistemas de ensino público para a promoção de sua oferta, com cobertura residual nas diferentes escalas dos poderes públicos da federação 
e em programas focalizados para elevação de escolarização (HADDAD e DI PIERRO, 2000; MACHADO, 2009; RUMMERT, 2007).

Produzidos por estas fontes, os sentidos sobre a EJA se inscrevem na materialidade da linguagem jurídica sendo reconhecida como um direito a ser reparado pelo Estado e as suas garantias estão declaradas no ordenamento constitucional e regulamentadas em documentos que a este contrato se vinculam. Os sentidos de suas funções, normatizadas pelas Diretrizes Curriculares Nacionais, completam o circuito legal através do qual a EJA é reconhecida como direito, cujo principal desdobramento é a garantia de sua oferta pelo poder público. (CURY, 2002).

Por sua vez, os sentidos sobre Política de Cotas, como um desdobramento mais visível das ações afirmativas, têm sua abrangência bastante ampliada pelo fato de nela terem se concentrado os debates sobre cotas para ingresso nas universidades públicas.

Destacamos o estudo de base historiográfica de Moehlecke (2002) ao inventariar que este termo chega ao Brasil carregado de sentidos, refletindo sobre os debates e experiências históricas dos países nos quais foram desenvolvidas as multiplicidades de ações. Ele explica que a discussão normativa acerca da validade das ações afirmativas, muito embora com sustentação legal, desde os anos de 1990, ainda tem sido objeto de interpretações relativas ao seu cumprimento pelas instituições do Estado brasileiro.

Em suas polissemias, a EJA e a Política de Cotas passaram a designar intervenções do Estado para garantir o cumprimento de direitos sociais não assegurados ou parcialmente acessíveis à população e buscaram seus sentidos no fundamento jurídico radicado nas lutas políticas pela redemocratização do estado brasileiro gravando o seu reconhecimento na Constituição de 1988 na qual o princípio da igualdade ganha conteúdo formal e normativo.

Para além do escopo jurídico, entende-se que, para produzir sentidos sobre a relação entre EJA e Política de Cotas, é preciso buscar no processo histórico da formação social brasileira o terreno no qual as desigualdades, tanto no aspecto econômico quanto cultural, questionam o discurso jurídico da justiça social.

Ao retomar o diálogo com Bastide e Fernandes, em "Negros e brancos em São Paulo" (1959), Ianni (2004, p. 10) afirma que "a realidade do preconceito racial de par em par com o preconceito de classe" expõe contradições inerentes às formas de democratização de acesso ao ensino superior pela Política de Cotas. Para Ianni, as cotas são uma conquista e uma concessão, uma legitimação de uma sociedade preconceituosa. 
E, em vez de enfrentarmos o problema na raiz - melhorando as condições sociais de brancos e negros de diferentes níveis sociais - se estabelece a cota. Não se mexe na ordem social que é uma fábrica de preconceitos, mas somente num nível restrito, que é o nível do acesso a certos espaços. É uma negação da idéia de democracia racial porque se ela existe, todos estão participando em situação de igualdade, mas sabemos que não é isso o que acontece. É também muito cruel, já que futuramente as elites dirão: "por que vocês estão reclamando? Nós abrimos espaços em nossas repartições públicas, nas universidades, etc. Como se isso fosse a conquista plena, quando na realidade é um contrabando de concessão (IANNI, 2004, p. 24).

O que Ianni instiga a pensar é que a reserva de cotas, dentro das políticas públicas de ações afirmativas, se constitui numa questão que deva ser complexificada, pois exige enfrentar as determinações sociais que a produziram e a demandaram.

Em síntese, as abordagens críticas oferecidas pelos autores referenciados atentam para o fato de que em suas complexidades, a EJA e a Política de Cotas acusam os efeitos das desigualdades tributárias da formação histórico-social da sociedade brasileira, cujos sentidos continuam a reverberar posições, pontos de vistas sobre a realidade brasileira.

Na seção seguinte, apresentamos o campus empírico da pesquisa concentrando nos dados coletados por meio de instrumento de questionário semiestruturado. Esclarecemos que privilegiamos alguns quesitos deste instrumento pelos limites da escrita em sua forma de artigo.

\section{0 contexto institucional e os resultados da pesquisa}

A pesquisa empírica foi realizada na FFP/UERJ, no período de 2015 a 2018. Esta unidade acadêmica está situada em São Gonçalo, município da Região Metropolitana do Rio de Janeiro, com mais de um milhão de habitantes (IBGE/2016) é o segundo município mais populoso do estado.

Contraditoriamente, a forte e contínua densidade demográfica e o destaque econômico atribuído ao município no setor de serviços e comércio não têm refletido em melhorias da qualidade de vida e educação para sua população. 0 município exibe profundas marcas do modelo de desenvolvimento desigual que materializam efeitos próprios da combinação entre o arcaico e o moderno, produzindo desigualdades sociais, 
não como anomalia, inerente a um determinado espaço-regional, mas como a forma pela qual a sociedade brasileira foi historicamente estruturada. (OLIVEIRA, 2006).

A FFP/UERJ é a segunda maior unidade acadêmica em termos de estudantes matriculados da UERJ e oferece atualmente 6 (seis) cursos de graduação de licenciatura plena, 9 (nove) cursos de Pós-Graduação Lato Sensu, 8 (oito) cursos de Pós-Graduação Stricto Sensu mestrado, sendo 7 (sete) em nível de Mestrado e 1 (um) em nível de em História Social. O Programa de Pós-Graduação Mestrado Acadêmico em Educação Processos Formativos e Desigualdades Sociais (PPGEdu-PFDS), em 2018, teve aprovado o curso de Doutorado em Educação pela CAPES com início de suas atividades para o ano de 2019.

A base documental foi organizada através de fontes institucionais que trabalham diretamente com o sistema de cotas da universidade, sendo elas a Coordenadoria de Articulação e Iniciação Acadêmicas (CAIAC), órgão responsável pela implementação das cotas na UERJ, o Programa de Iniciação Acadêmica (Proiniciar), criado para apoiar estudantes na perspectiva de garantir sua permanência na universidade e viabilizar o cumprimento da Lei no 5346/08. Estes órgãos trabalham com informações para uma composição do perfil dos estudantes cotistas da universidade. 0 acesso a essas fontes foram fundamentais para chegarmos aos estudantes cotistas da faculdade e entre os quais os egressos da escola EJA/EM.

Através do Núcleo de Informação e Estudos de Conjuntura da UERJ (NIESC), acessamos o anuário estatístico onde estão publicadas tabelas de dados e relação de indicadores da estrutura e de evolução em relação ao corpo discente e docente da instituição. Para a pesquisa utilizamos a publicação DataUERJ 2017, referente aos dados de 2016.

Ressaltamos que não existem informações que revelem qual a modalidade de certificação do EM pelos estudantes ingressantes. Desse modo, até o momento, não existe, em nenhum questionário de ingresso ou levantamento socioeconômico disponibilizados por estes sistemas, uma questão que indique se os estudantes matriculados concluíram o EM pela modalidade EJA ou não, limitando-se, conforme o objetivo dos sistemas de informação, a identificar se esses alunos são egressos de escolas públicas ou privadas.

O primeiro estudo realizado pelo CAIAC sobre ingresso de estudantes pelo sistema de cotas descreve que, entre 2003 e o primeiro semestre de 2012, ingressaram na universidade 47.540 estudantes, dos quais 15.935 eram cotistas. Mas, no ano de 2016, 
ALVARENGA, M.S.; SANTOS, C. Egressos da EJA no ensino superior e a política de cotas da UERJ: entre desafios e potencialidades

pela primeira vez desde que foi prorrogada a Lei $\mathrm{n}^{0}$ 5346/08, esta coordenadoria detectou número menor de cotistas em relação ao que foi determinado pelo edital do vestibular de 2015 .

Dados processados pelo DataUERJ/ 2017 constatam que, mesmo não tendo sido atingido o percentual de $45 \%$ de reserva de vagas para estudantes cotistas, entre os 22.706 estudantes com matrículas ativas nos cursos de graduação, 8.012 eram cotistas. Somente no vestibular de 2017, ingressaram 1.007 (33\%) estudantes por este sistema, dentre os 3.071 estudantes matriculados iniciais nos cursos de graduação.

A diferença entre o número de matrículas de estudantes que ingressaram pelo sistema de cotas entre 2012 e 2017 merece ser compreendida em leitura de conjuntura. Uma hipótese pode ser construída em virtude da recente crise geral da UERJ que amplificou e tornou mais visível um conjunto de problemas enfrentados pela universidade que, em crise econômica, sem autonomia de gestão financeira, sem recursos e com salários atrasados de pessoal terceirizado, de salários de professores e de bolsas das diferentes modalidades, teve a primeira suspensão do calendário acadêmico em março de 2015 e, a segunda, em agosto de $2017^{3}$.

Na conjuntura da crise do estado e da UERJ, Frigotto (2017) analisou que:

A crise do estado do Rio de Janeiro e a Uerj expressam o modelo que servirá para o conjunto dos estados e de suas instituições públicas. Vale ressaltar: por vinte anos, seguirão a PEC 55 e nenhum dinheiro a mais para a esfera pública. Com efeito, o acórdão da austeridade da PEC, que envolve o parlamento, o Poder Judiciário e o Poder Executivo, apoiado pela grande mídia, é pressuposto para suspender, unicamente por três anos, os juros da dívida do estado do Rio de Janeiro com a União, mas com a contrapartida que, além de não ter mais investimento em educação, saúde e serviços públicos, a crise e a dívida do estado têm de ser assumidas pelos trabalhadores do serviço público (FRIGOTTO, 2017, p. 55).

Se por um lado creditamos à crise da UERJ o reduzido número de candidatos para o vestibular de 2016 e 2017, por outro lado a ocorrência de um aumento da procura pelo ingresso no ensino superior, se deu, principalmente no setor privado, por meio de financiamentos, como o FIES e o PROUNI, o que não significa que os estudantes matriculados tenham permanecido e concluído seus estudos.

$\mathrm{Na}$ crítica sobre os modelos de expansão do Ensino Superior pela via do financiamento público para a as instituições privadas, Leher $(2004$, p. 871) discute que, o

\footnotetext{
${ }^{3}$ Sobre o repertório de crises da UERJ, indicamos a tese de doutorado de Silva (2018) "UERJ em movimento: da resistência democrática à democracia da (re)existência (1985/2016)".
} 
ALVARENGA, M.S.; SANTOS, C. Egressos da EJA no ensino superior e a política de cotas da UERJ: entre desafios e potencialidades

que é mostrado, é "a imagem de que, doravante, os muito pobres, os negros e os egressos das escolas públicas finalmente terão acesso à educação superior" e conclui que a essência deste modelo é o estabelecimento de Parcerias Público-Privado no campo da educação.

Sobre isto, Vargas e Paula (2013) chamam a atenção para uma tendência de baixo crescimento da educação, em controvérsia à campanha de expansão do ensino superior e refletem sobre o fato de que os potenciais estudantes universitários - a quem deveria se destinar as políticas de cotas - vivem em condições socioeconômicas tão desfavoráveis, que sequer aspiram ingressar no ensino superior. A hipótese operada pelas autoras é de que

(...) a ênfase na política de ampliação do acesso não esgota o projeto de democratização da educação superior. Esse processo só se completará se tivermos igual proporção de crescimento na taxa de concluintes, com inclusão crescente das camadas marginalizadas socialmente, sobretudo os estudantes de baixa renda (VARGAS; PAULA, 2013, p. 464).

Nos resultados apresentados a seguir, tratamos sobre os dados dos estudantes da graduação da FFP/UERJ. A pesquisa empírica permitiu exposições de tabelas e gráficos para variáveis categóricas qualitativas, devido ao escopo do questionário e variáveis presentes no registro de estudantes.

Optamos por trabalhar com valores absolutos nos gráficos oriundos dos questionários. Essa decisão tem por objetivo materializar a quantidade de respondentes, devido ao possível problema de categorias de respostas que pudessem apresentar um número reduzido de estudantes que respondessem ao questionário. Em especial isso ocorreu nas tabulações bivariadas segundo tipo de cota.

Frente a quantidade de gráficos e tabelas elaboradas, optamos por apresentar apenas as consideradas mais relevantes para o presente artigo. Os resultados têm por objetivo utilizar estatísticas descritivas das bases de dados dos estudantes ativos da FFP/UERJ e os cotistas que concluíram o ensino médio nas modalidades, EJA, Exame Nacional para Certificação de Competências de Jovens e Adultos (ENCCEJA) e Supletivo4.

Nesse sentido, esse subitem está estruturado em duas seções. A primeira delas destinada a traçar o perfil dos estudantes da FFP com matrícula ativa até $2016 / 2$. A

\footnotetext{
${ }^{4}$ O termo "Supletivo" era designado pela LDBno $4024 / 61$ como forma de oferta de cursos para certificação de $1^{\text {o }}$ e 2 o grau. Muito embora a LDB 9394/96 tenha revogado o ensino supletivo e estabelecido a EJA como modalidade de oferta educacional, parece que esta nomenclatura se mantém no imaginário de jovens e adultos egressos da EJA. Por esta razão, e em consonância com o nosso referencial teórico-epistemológico, mantivemos o termo como sentido produzido pelos cotistas.
} 
segunda tem o objetivo de traçar um perfil dos estudantes que foram selecionados na amostra (sendo eles os 56 que responderam ao questionário), a partir de questões relacionadas a aspectos demográficos, laborais, de ensino, município de moradia e formação dos pais.

Ao nos debruçarmos sobre os dados de 2016, os cursos de licenciaturas oferecidos pela unidade acadêmica registravam um total de 1.959 estudantes com matrículas ativas. Deste total, 495 corresponderam a estudantes cotistas. Devido a amostra reduzida em algumas variáveis, optou-se por apresentar as tabulações por número absoluto, possibilitando uma melhor observação dos volumes amostrais que poderiam ser passados despercebidos caso fossem apresentados os resultados por números relativos.

O curso com maior número de estudantes ativos na faculdade, até 2016/2, incluindo os estudantes que ingressaram por ampla concorrência e por cotas, foi o curso de Geografia (435); e o que apresentou o menor número de ativos é o de Matemática (162). Dos dados levantados pelo SAG, o curso que tem mais ingressantes cotistas é o de História (114) e o curso que menos apresenta estudantes cotistas é o de Matemática (27).

A partir destes dados delineamos o perfil dos estudantes da FFP/UERJ, com duas qualificações: a) composição dos ingressantes no vestibular de 2016/2, delimitando os ingressantes cotistas e não cotistas, por curso de graduação; b) perfil dos estudantes ingressantes por tipos de cotas.

No Gráfico 1, apresentamos o quantitativo de matrículas ativas nos cursos de graduação distribuídos entre cotistas e não cotistas. Chegamos ao número de estudantes potenciais que poderiam responder ao questionário para procedermos à descrição de perfil socioeconômico dos cotistas, a fim de levantarmos quem são e quantos são os estudantes ativos que concluíram o ensino médio através da EJA/EM ou comprovaram estratégias de certificação nesta etapa da Educação Básica. Até 2016/2 a FFP/ UERJ contava com 1959 estudantes ativos, distribuídos nos 7 (sete) cursos, dentre eles 435 cursavam Geografia, 337 Pedagogia, sendo os dois cursos com mais estudantes e 162 em Matemática, o curso com menos estudantes. 
ALVARENGA, M.S.; SANTOS, C. Egressos da EJA no ensino superior e a política de cotas da UERJ: entre desafios e potencialidades

Gráfico 1- Distribuição dos estudantes ativos da FFP segundo curso até 2016/2

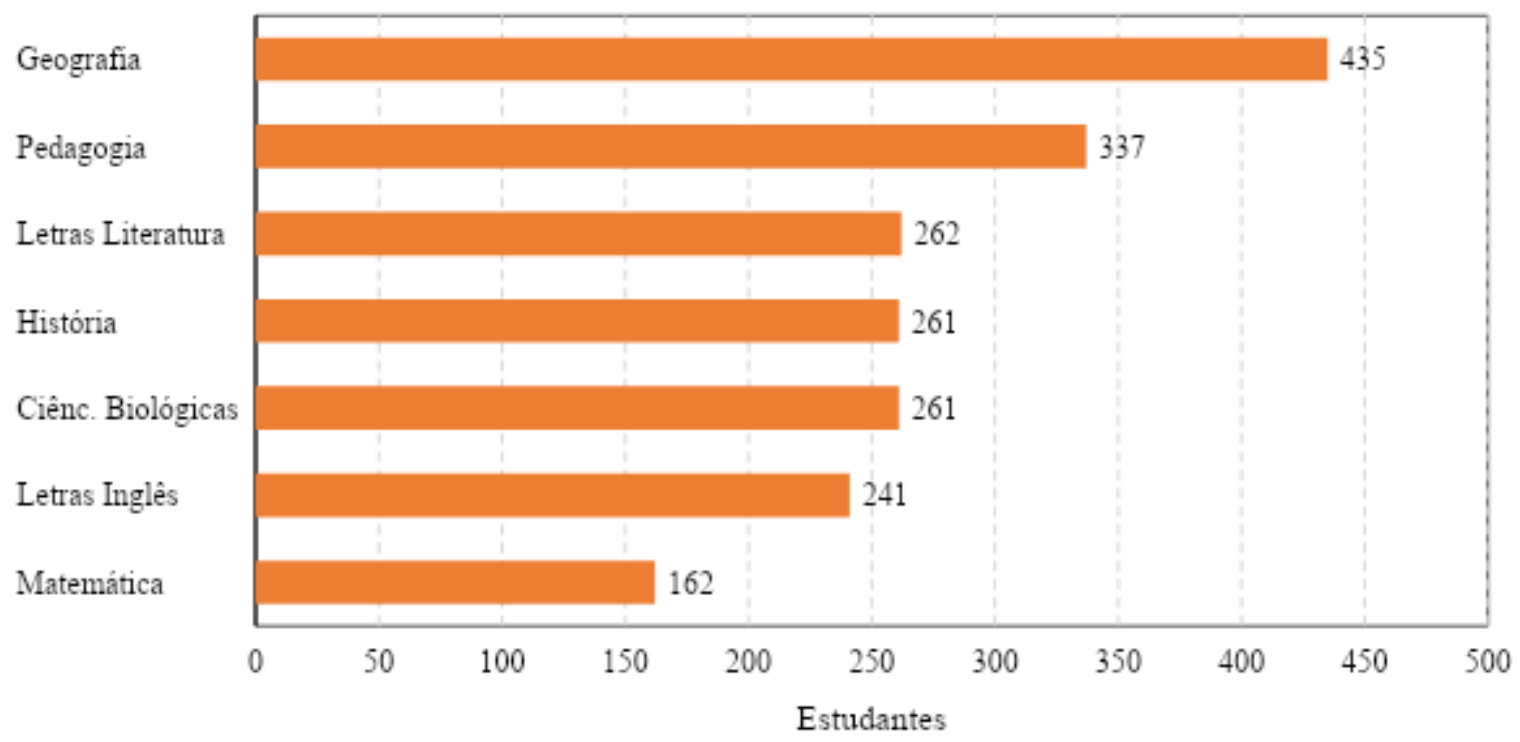

Fonte: DataUERJ, 2017.

A partir do volume de estudantes matriculados até 2016/2, pudemos mensurar o percentual de cotistas por curso (Tabela 1). Foi a partir destes resultados que verificamos que a FFP/UERJ não atingiu os percentuais para as cotas, conforme determinação do edital do vestibular de 2015.

Em relação às cotas nas licenciaturas, a tabela a seguir informa sobre os cursos de maior interesse dos cotistas:

Tabela 1 - Percentual de Cotistas da FFP segundo curso até 2016/2

\begin{tabular}{|c|c|c|c|c|c|}
\hline \multirow[t]{2}{*}{ Curso } & \multicolumn{2}{|c|}{ Ativos (A) } & \multicolumn{2}{|c|}{ Cotistas (B) } & \multirow[t]{2}{*}{$\begin{array}{l}\text { Cotistas (\%) } \\
\left(\frac{A}{B}\right) \times 100\end{array}$} \\
\hline & Freq. & $\%$ & Freq. & $\%$ & \\
\hline Matemática & 162 & 8,27 & 27 & 5,45 & 16,67 \\
\hline Geografia & 435 & 22,21 & 104 & 21,01 & 23,91 \\
\hline História & 261 & 13,32 & 112 & 22,63 & 42,91 \\
\hline Letras Inglês & 241 & 12,30 & 48 & 9,70 & 19,92 \\
\hline Letras Literatura & 262 & 13,37 & 63 & 12,73 & 24,05 \\
\hline Pedagogia & 337 & 17,20 & 63 & 12,73 & 18,69 \\
\hline Ciênc. Biológicas & 261 & 13,32 & 78 & 15,76 & 29,89 \\
\hline Total & 1959 & 100,00 & 495 & 100,00 & 25,27 \\
\hline
\end{tabular}

Fonte: SAG, 2017. 
ALVARENGA, M.S.; SANTOS, C. Egressos da EJA no ensino superior e a política de cotas da UERJ: entre desafios e potencialidades

Ao final deste processo, compomos um panorama geral dos cotistas da faculdade com informações referentes aos 495 estudantes que eram identificados como ativos na listagem da equipe técnica. Constatamos que neste total, 10 estudantes trancaram a matrícula no decorrer do ano de 2017 e 16 estudantes concluíram os cursos.

Efetivamente permaneceram ativos 469 estudantes. Entretanto, não conseguimos contato por e-mail e telefone com 41 estudantes, o que resultou em um total de 428 estudantes com os quais conseguimos colher informações. Detectamos que 10 estudantes foram registrados como sendo egressos da EJA, 1 (um) estudante fez o ENCCEJA e 9 (nove) estudantes concluíram o Ensino Médio (EM) por estudos supletivos.

Tabela 2- Distribuição de Cotistas da FFP por curso, segundo modalidade de formação no Ensino Médio

\begin{tabular}{|c|c|c|c|c|c|c|c|c|}
\hline \multirow{2}{*}{ Curso } & \multicolumn{2}{|c|}{ Regulares } & \multicolumn{2}{|c|}{ EJA } & \multicolumn{2}{|c|}{$\begin{array}{c}\text { Supletivo / } \\
\text { ENCCEJA }\end{array}$} & \multicolumn{2}{|c|}{ Total } \\
\hline & Freq & $\%$ & Freq. & Freq. & Freq. & $\%$ & Freq. & $\%$ \\
\hline Matemática & 25 & 1,28 & 0 & 0,00 & $1 / 0$ & 3,85 & 26 & 6,07 \\
\hline Geografia & 79 & 19,36 & 2 & 20,0 & $2 / 1$ & 30,00 & 84 & 19,63 \\
\hline História & 100 & 24,51 & 5 & 50,00 & $2 / 0$ & 20,00 & 107 & 25,00 \\
\hline Letras Inglês & 36 & 8,82 & 2 & 20,00 & $2 / 0$ & 20,00 & 40 & 9,35 \\
\hline Letras Literatura & 50 & 12,25 & 1 & 10,00 & $2 / 0$ & 20,00 & 53 & 12,38 \\
\hline Pedagogia & 51 & 12,50 & 0 & 0,00 & $0 / 0$ & 0,00 & 51 & 11,92 \\
\hline Ciênc. Biológicas & 67 & 16,42 & 0 & 0,00 & $0 / 0$ & 0,00 & 67 & 15,65 \\
\hline Total & 408 & 100 & 10 & 100,00 & 10 & 100,00 & 428 & 100,00 \\
\hline
\end{tabular}

Fonte: SAG e questionário da pesquisa, 2017.

O percentual de estudantes que concluiu o EM regular foi de 95,1\% do total de estudantes ativos. Apenas 2,45\% dos estudantes cotistas ativos, até 2016/2, foram egressos da EJA/EM ou obtiveram certificação de conclusão do EM pelo ENCCEJA.

Estas perspectivas parecem dialogar com o perfil delineado dos estudantes cotistas e dos egressos da EJA/EM que responderam ao questionário. Considerando a idade média dos respondentes, verificamos que mais da metade deles tem menos de 24 anos (58,9\%). Em relação ao estado civil 87,5\% são solteiros (49). Do total de estudantes, 
$41 \%$ destes se auto declararam ${ }^{5}$ negros (23), superando o número de estudantes autodeclarados brancos (19) e pardos (14).

Identificamos que a maior parte dos respondentes é do sexo feminino (43 mulheres), o que equivale a 76,7\% dos estudantes cotistas. Estas informações corroboram sobre os resultados do censo da educação superior de que, considerando as instituições públicas e privadas, 71,7\% das matrículas em cursos de licenciatura são do sexo feminino, enquanto 28,9\% são do sexo masculino (INEP, 2016). Mas, também, acentua a potência das cotas para o acesso e representação das mulheres na universidade.

De acordo com a inserção laboral, constatou-se que todas as formas de trabalho apresentadas tiveram ingressantes por escola pública, onde $46,1 \%$ que são trabalhadores com vínculo formal de trabalho, 81,9\% são trabalhadores com vínculo informal e 62,5\% dos estudantes que não trabalham ingressaram pela escola pública. Do total de respondentes $26,8 \%$ optaram por ingressar por cota racial e $10,8 \%$ relataram terem ingressado por cota de renda.

Sobre a escolarização dos pais, a pesquisa identificou que os pais de 25 estudantes cursaram até o ensino fundamental (44,6\%). 0 Ensino Médio era a formação dos pais de 24 estudantes $(42,9 \%)$ e 7 (sete) estudantes eram de famílias cujos pais tinham formação no Ensino Superior e/ou na pós-graduação (12,5\%).

Gráfico 1 - Distribuição da escolarização dos pais

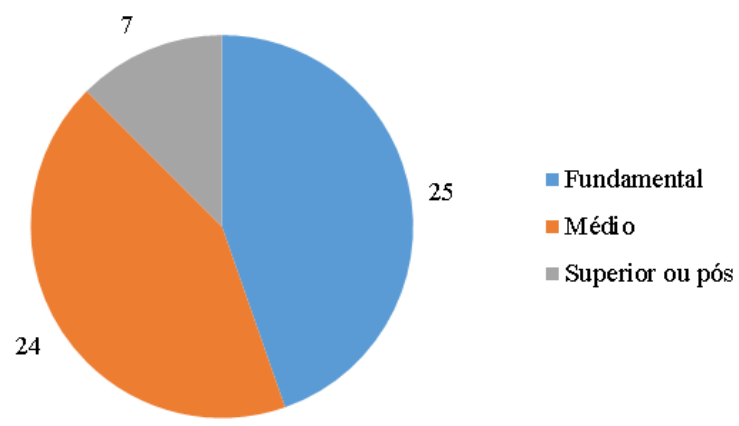

Fonte: Questionário da pesquisa, 2017.

De acordo com o Gráfico 2, em todos os cursos de licenciaturas predominou a modalidade de ingresso por cotas da escola pública. 0 curso de Ciências Biológicas teve

\footnotetext{
${ }^{5} \mathrm{~A}$ autodeclaração racial dos candidatos às cotas da UERJ passou a ser documentação obrigatória aos candidatos determinada pela Lei no $\mathbf{0} 346 / 2008$.
} 
ALVARENGA, M.S.; SANTOS, C. Egressos da EJA no ensino superior e a política de cotas da UERJ: entre desafios e potencialidades

destaque na pesquisa, pois todos os estudantes cotistas que responderam ao questionário são oriundos desta modalidade de cotas.

Gráfico 2- Distribuição dos respondentes por modalidade de cotas, segundo curso de Licenciatura

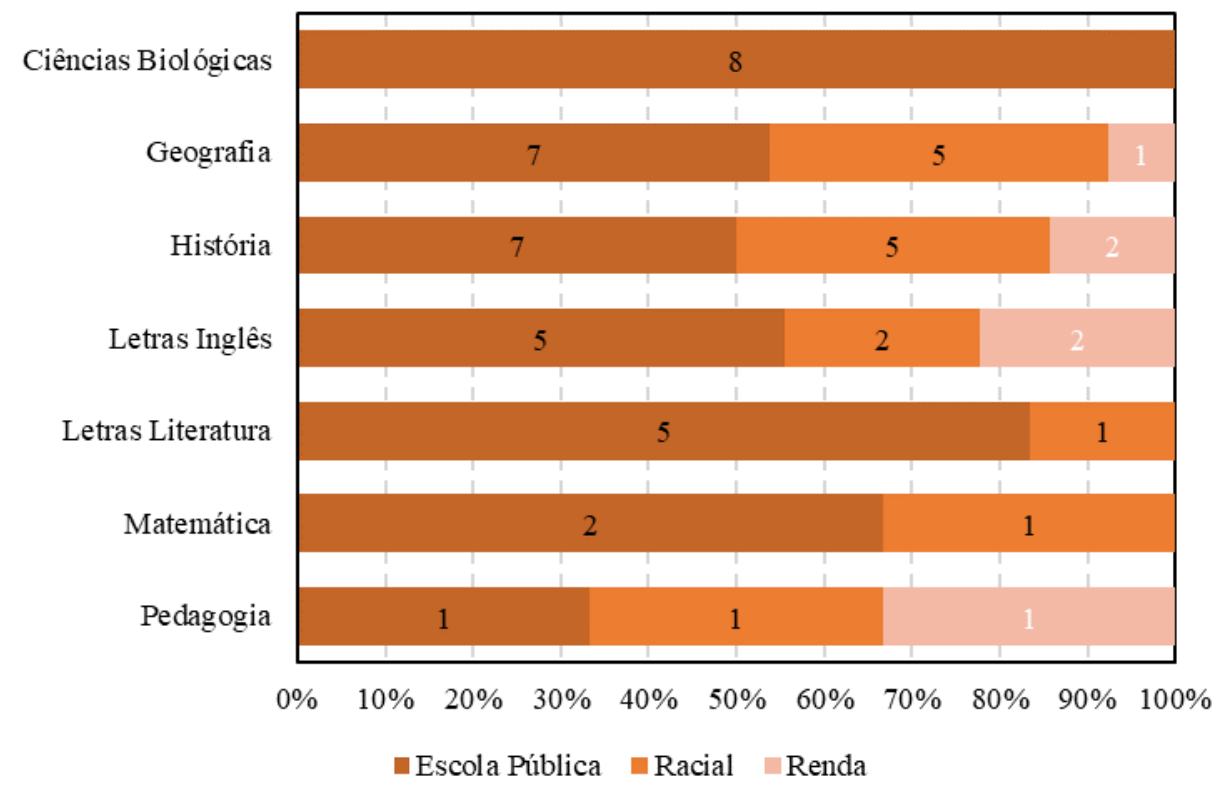

Fonte: Questionário da pesquisa, 2017.

$\mathrm{Na}$ tabela 2, o percentual de estudantes que concluíram o EM, sem ser na modalidade EJA, correspondeu a 95,1\% do total de estudantes ativos. Apenas 2,45\% dos estudantes cotistas ativos até 2016/2 foram egressos desta modalidade. Identificamos que 2 (dois) estudantes egressos da EJA/EM ingressaram por cota optando, respetivamente, pela cota de escola pública e pela cota racial. Através do ENCCEJA, 1 (um) estudante ingressou por cota racial. Em relação aos egressos de Estudos Supletivo, 2 (dois) estudantes são deles egressos.

É necessário, porém submeter a um olhar crítico sobre as modalidades de certificação com perspectiva discursiva de inclusão, que têm o que Kuenzer (2005) denomina de "certificação vazia", como forma aparente de inclusão.

Quando verificamos os estudantes concluíram o EM regular constatou-se que 91\% optou pela cota de escola pública $(62,8 \%), 25,5 \%$ ingressaram por cota racial e $11,7 \%$ informaram ter ingressado por renda. Ressaltando que todos os estudantes que relataram terem ingressado por renda concluíram o EM regular. 
Gráfico 3- Distribuição dos respondentes por modalidade de cota, conforme modalidade de conclusão e certificação do Ensino Médio

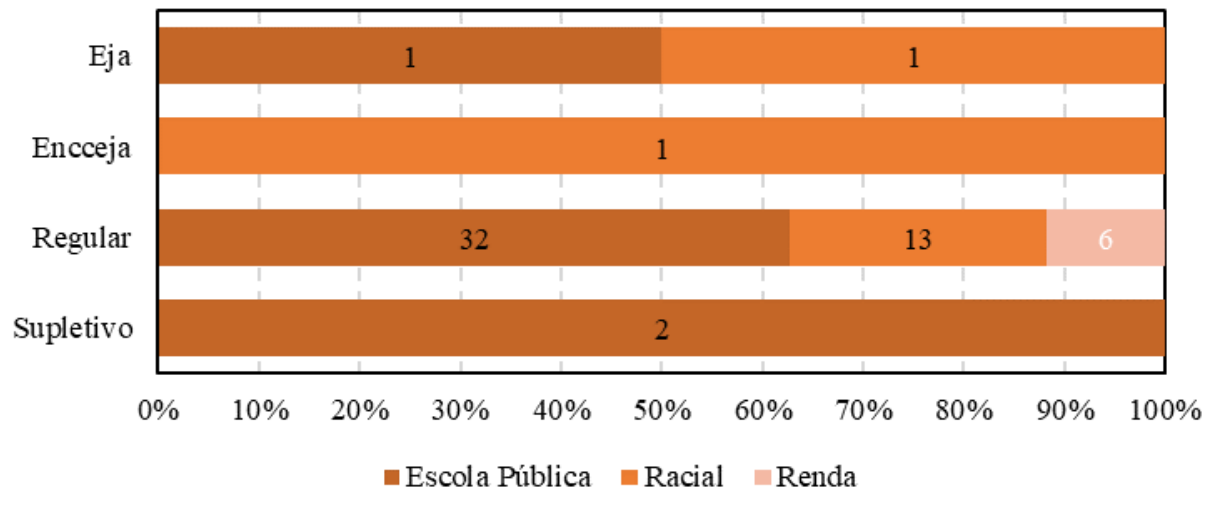

Fonte: Questionário da pesquisa, 2017.

Podemos observar que todos os respondentes oriundos de instituição particular ingressaram por cotas raciais. Sendo 71,4\% que se formaram em instituição pública também optaram pelo ingresso por escola pública, vindo em segundo lugar a cota racial $(16,3 \%)$ e por último declararam o ingresso por renda $(12,3 \%)$.

Este perfil já havia chamado atenção de Machado (2005) ao escrever o que talvez seja a mais importante descoberta da sua tese de doutorado (sic), tendo como sujeitos da pesquisa estudantes cotistas da UERJ:

Beneficiados pela primeira lei (de reserva para egressos de escolas públicas), 798 candidatos "negros e pardos" obtiveram vagas na Uerj. Enquanto apenas 331 vestibulandos incluídos nesta categoria ingressaram na universidade pela segunda lei (de cotas para negros ou pardos). Ou seja, entre os 1.968 que "se autodeclaram como negros e pardos" que passaram no vestibular, a grande maioria, cerca de $80 \%$, garantiu sua matrícula na universidade independentemente da lei de cotas para negros e pardos (MACHADO, 2005, p. 31).

Os dados apresentados pela autora são referentes ao vestibular de 2003, primeiro ano em que o vestibular da UERJ determina a reserva de vagas de corte racial. Ou seja, essa parece ser uma tendência na UERJ, não sendo um dado restrito à FFP/UERJ. Desde a implantação da Política de Cotas, o ingresso pelo corte da escola pública se mantém como primeira opção frente à cota racial.

Sobre muitas possibilidades de inferências, não podemos ignorar os dados de matrículas para a modalidade de EJA que registraram, desde 2008 a 2016, forte retração, tanto na etapa da Educação Fundamental, quanto do Ensino Médio, não tendo se 
mostrado em tendência de reversão nos anos subsequentes. Dados do Censo Escolar INEP/2016, indicam que a EJA, nos anos iniciais, começou o ano de 2008 com 1.127.077 matrículas e, em vertiginosa queda, chegou em 2016 com 628.393 matrículas. No Ensino Médio, foram registradas 1.635.245, decrescendo para 1 (uma). 341.841 matrículas em 2016, uma redução de quase 300 mil matrículas.

Sobre essa tendência, Fávero (2011) enfatiza ser a queda de matrículas na EJA tributária de fatores diversos, entre eles conciliar trabalho e estudo. Considera, também, que são poucos os municípios que apresentam experiências consolidadas que atendam às necessidades e condições de acesso e permanência de jovens e adultos na EJA.

O autor destaca o acúmulo de problemas e políticas não resolvidas para a EJA. Entre outras, à idade mínima para o ingresso e conclusão na EJA, a articulação entre o ensino médio e profissional; a necessidade de se avaliar a proposta do ENCCEJA, bem como enfrentar os efeitos deletérios da competição entre os programas sociais com viés de focalização e de curta duração destinados ao público potencial da EJA.

Considerando a população brasileira com 15 anos ou mais, a partir do Censo Demográfico de 2010, foi gerado o indicador Demanda Potencial para a EJA - Ensino Fundamental (DPEJAF). Com este indicador questiona-se a oferta da EJA pelos poderes municipais que reduziram, acentuadamente, as possibilidades de que jovens e adultos possam acessar a EJA.

As discussões em torno da retração das matrículas na EJA e os modelos de escolarização via programas com contornos de profissionalização sugerem, entre outras, que nesta modalidade está subsumido o caráter de terminalidade escolar, segundo o qual marca o fim de um processo educacional, o que implica interpelar sobre a concretude de realização do direito à educação de egressos da EJA em projetar possibilidades de acessar o Ensino Superior.

Os dados mapeados pela pesquisa indicam que ao considerarmos, exclusivamente, a cota para estudantes da rede pública, as restrições de renda familiar e da qualidade da escola pública frequentada limitam o número de candidatos cotistas que buscam acesso à universidade pública. No entanto, a Política de Cotas permanece como potente política para a democratização de acesso ao Ensino Superior para egressos da EJA. 
ALVARENGA, M.S.; SANTOS, C. Egressos da EJA no ensino superior e a política de cotas da UERJ: entre desafios e potencialidades

\section{Conclusões}

A pesquisa teve por objetivo abordar um aspecto ausente na literatura sobre EJA e Política de Cotas com vistas a uma proposição analítica sobre o enlace entre a modalidade da EJA e Política de Cotas.

Os desafios e potencialidades da Política de Cotas para egressos da EJA, no contexto empírico da pesquisa, expôs relações entre variáveis qualitativas que circunstanciaram o perfil socioeconômico dos estudantes. A quantificação da frequência, porém, não dão conta de todos os desdobramentos possíveis, mas apoiam a matriz interpretativa qualitativa do estudo sobre enunciação das fontes trabalhadas, cujos sentidos produzidos expressaram alguns dos desafios e potencialidades da Política de Cotas na UERJ/FFP em seu enlace com a EJA.

Contradições sobre condições da oferta da EJA e a Política de Cotas extrapolam a quadra da linguagem jurídica. Os resultados enunciaram que o acesso à universidade pelos egressos da EJA refletiu e refratou para fora os seus sentidos. Vale dizer, que os escopos gravados no domínio constitucional e legislações derivadas são insuficientes para materializar o direito à educação.

A despeito dos limites da pesquisa, pode-se admitir que pouco sabemos sobre os sujeitos da EJA, após concluírem a EJA/EM. É necessário aperfeiçoar os sistemas de coleta de informações das instituições de ensino, inserindo, nos instrumentos dos bancos de dados, questões que informem sobre ingressantes cotistas: turno que frequentaram, origem de certificações (ENCCEJA) estimuladas pelos poderes públicos, entre outros.

Embora a pesquisa esteja empiricamente contextualizada em uma unidade acadêmica da UERJ, há possibilidades de diálogos com outras instituições de ensino e na própria UERJ, em particular. A troca de informações sobre egressos da EJA pela Política de Cotas sugere estudos comparativos e/ou de caso em abordagens sobre este enlace temático.

Ressaltou-se que os históricos desafios da EJA se avolumam por ser esta uma modalidade gravada por múltiplas desigualdades estruturalmente produzidas. A despeito do manto declaratório da EJA como um direito, os resultados da pesquisa estão abertos a interrogar sobre os desdobramentos da função equalizadora da EJA como móvel de acesso ao Ensino Superior.

Enfatiza-se que o projeto societário que saiu vitorioso nas eleições para a presidência da República e na maioria dos estados brasileiros, no ano de 2018, explicitou 
que os processos de dominação no Brasil mantêm o seu projeto de poder, reiterando e aprofundando a apartação de trabalhadores jovens e adultos pobres, negros, mulheres, indígenas, segmentos LGBTs, combinado com a criminalização dos movimentos sociais do campo democrático.

Em diálogo com as referências bibliográficas recorridas vimos que elas continuam seminais nas análises sobre a relação entre as clivagens de classe, de raça e de gênero e a democratização do direito à educação em todos os níveis e modalidades.

Nestes processos, a minoria prepotente opressora sobre a maioria oprimida, na linguagem de Freire (2003), aprofundou o projeto de uma sociedade dependente subordinada aos interesses dos centros econômicos do capitalismo mundial, no qual o desafio educacional (FERNANDES, 2004) e as lutas pelo direito à educação nele se insere.

A conjuntura e condições pelas quais foi realizada a pesquisa, em um momento de profunda crise política e econômica do estado do Rio de Janeiro que atingiu profundamente a UERJ, alertam sobre a inadiável articulação entre forças políticas democráticas na defesa da escola e universidades públicas como patrimônio inalienável da sociedade brasileira.

\section{Referências}

BAKHTIN, M. Estética da criação verbal. São Paulo: Martins Fontes, 2000.

BEISIEGEL, C. Estado e educação popular: um estudo sobre educação de adultos. São Paulo: Pioneira, 1974. (Biblioteca Pioneira de Ciências Sociais).

BRASIL. Lei no 12.711, de 29/08/2012. Dispõe sobre o ingresso nas universidades federais e nas instituições federais de ensino técnico de nível médio e dá outras providências.

Parecer CEB11/2000 - Diretrizes curriculares nacionais para a educação de jovens e adultos. In: SOARES, Leôncio. Educação de jovens e adultos. Rio de Janeiro: DP\&A, 2002. p. 25-133.

BEVILÁQUIA, C. Entre o previsível e o contingente: etnografia do processo de decisão sobre uma política de ação afirmativa. In. Revista de Antropologia, n. 1, v. 48. São Paulo: USP, 2005, 167-225. Disponível em <http://www.scielo.br/pdf/ra/v48n1/a05v48n1.pdf>. Acesso em: 20/02/2018. 
CURY, C. R. J. (Relator). Diretrizes Curriculares Nacionais para a Educação de Jovens e Adultos. Parecer CNE/CEB, aprovado em 10 de maio de 2000. Disponível em: <http://portal.mec.gov.br/secad/arquivos/pdf/eja/legislacao/parecer_11_2000.pdf> Acesso em: 17 de fevereiro de 2017.

FÁVERO, O. Políticas públicas de educação de jovens e adultos no Brasil. In. SOUZA, J; SALES, S. (Orgs.). Educação de Jovens e adultos: políticas e práticas educativas. Rio de Janeiro: NAU, 2011.

( (Org.). Cultura popular, educação popular: memória dos anos 60. Rio de Janeiro: Graal, 1983.

FERES JÚNIOR; ZONINSEIN, J (Orgs.). Ação afirmativa e universidade: experiências nacionais comparadas. Brasília: UnB, 2006.

FERNANDES, F. Capitalismo dependente e classes sociais na América Latina. Rio de Janeiro: Zahar Editores, 2004.

FREIRE, P. Pedagogia do Oprimido. Rio de Janeiro: Paz e Terra, 2003.

FRIGOTTO, G. O Golpe de Estado e o desmanche da universidade e da esfera pública. In: MARCEL, P; PAVAN, Y; SIQUEIRA, M. (Orgs.). Hoje acordei para a luta: intelectuais em defesa da universidade pública. RJ: EDUERJ, 2017. pp. 49-59.

HADDAD, S; PIERRO,.Di, M.C. Escolarização de Jovens e Adultos. Revista Brasileira de Educação, $\quad n^{0}$ 14, maio/agosto, 2000. Disponível em <http://www.scielo.br/pdf/rbedu/n14/n14a07.pdf>. Acesso: 10/03/2016.

IANNI, O. Temas em debate entrevista Octávio Ianni: o preconceito racial no Brasil. In. Revista Estudos Avançados. Vol. 18, no 50. São Paulo, Jan./Apr. 2004. Disponível em <http://www.revistas.usp.br/eav/article/view/9965>. Acesso: 15/04/2017.

IBGE. Instituto Brasileiro de Geografia e Estatística. Disponível em: <https://cidades.ibge.gov.br/brasil/rj/sao-goncalo/panorama>. Acesso em: 17/02/ 2017.

INEP/MEC. Censo da Educação Superior de 2010. Disponível em: <http://download.inep.gov.br/educacao_superior/censo_superior/documentos/2010/ divulgacao_censo_2010.pdf>. Acesso em: 17/02/ 2017.

KUENZER, A. Z. Exclusão includente e inclusão excludente: a nova forma de dualidade estrutural que objetiva as novas relações entre educação e trabalho.In: LOMBARDI, J.; SAVIANI, D.; SANFELICE, J. (Orgs.). Capitalismo, trabalho e educação. $3^{a}$ ed. São Paulo: Autores Associados; HISTEDBR, 2005. p. 77 - 96. 
HERINGER, R.. Dez anos de ação afirmativa: mapas, balanços, aprendizados. In: Cadernos do GEA, n. 2. Rio de Janeiro: FLACSO, GEA; UERJ, LPP, 2012, p. 11-12.

LEHER, R.. Para silenciar os campi. In: Educação e Sociedade. Campinas, vol. 25, no8, outubro de 2004, p. $867 \quad$ - 891. $\quad$ Disponível em <http://www.scielo.br/pdf/es/v25n88/a11v2588.pdf>. Acesso: 30 08/2017.

MACHADO, E. A. Desigualdades "Raciais" e Ensino Superior: Um estudo sobre a introdução das Leis de reserva de vagas para egressos de escolas públicas e cotas para negros, pardos e carentes na Universidade do Estado do Rio de Janeiro (20002004). Tese (Doutorado em Ciências Sociais). Universidade Federal do Rio de Janeiro, 2005.

MACHADO, M. A educação de jovens e adultos no Brasil pós-Lei no 9.394/96: a possibilidade de constituir-se como política pública. Revista Em Aberto, vol. 22, n. 82, 2009.

Disponível

em

<http://emaberto.inep.gov.br/index.php/emaberto/article/view/2240>.

Acesso: 20/04/2017.

MOEHLECKE, S. Ação afirmativa: história e debates no Brasil. In. Cadernos de Pesquisa, São Paulo: Fundação Carlos Chagas; Campinas: Autores Associados, n. 117, p. 197- 217, nov. 2002. Disponível em <http://www.scielo.br/pdf/cp/n117/15559.pdf>. Acesso: $25 / 04 / 2017$.

OLIVEIRA, F. A dominação globalizada: estrutura e dinâmica da dominação burguesa no Brasil. En publicación: Neoliberalismo y sectores dominantes. Tendencias globales y experiencias nacionales. BASUALDO, E; ARCEO, E. CLACSO, Consejo Latino americano de Ciencias Sociales, Buenos Aires. Agosto 2006. Disponível em: <http://bibliotecavirtual.clacso.org.ar/ar/libros/grupos/basua/>. C08DeOliveira.pdf. Acesso em: 12/01/ 2017.

PAIVA, V. Educação Popular e Educação de Adultos. São Paulo: Ed. Loyola, 1978.

RIO DE JANEIRO. Lei 5346/08. Dispõe sobre o novo sistema de cotas para ingresso nas universidades estaduais e dá outras providências.

RUMMERT, S. M. A educação de jovens e adultos trabalhadores brasileiros no século XXI: o "novo" que reitera a antiga destituição de direitos. In. Revista de Ciência da Educação, Sísifo. jan. / abr., 2007, p. 35-50. Disponível em: <http://sisifo.fpce.ul.pt>. Acesso: 05/02/2019.

VARGAS, H.; PAULA, M. F. A inclusão do estudante-trabalhador e do trabalhadorestudante na educação superior: desafio público a ser enfrentado. In: Revista da Avaliação da Educação Superior (Campinas), vol. 18, no 2, julho de 2013, p. 459-485. 
ALVARENGA, M.S.; SANTOS, C. Egressos da EJA no ensino superior e a política de cotas da UERJ: entre desafios e potencialidades

Disponível em <http://www.scielo.br/pdf/aval/v18n2/11.pdf>. Acesso em: 26/03/2017. 

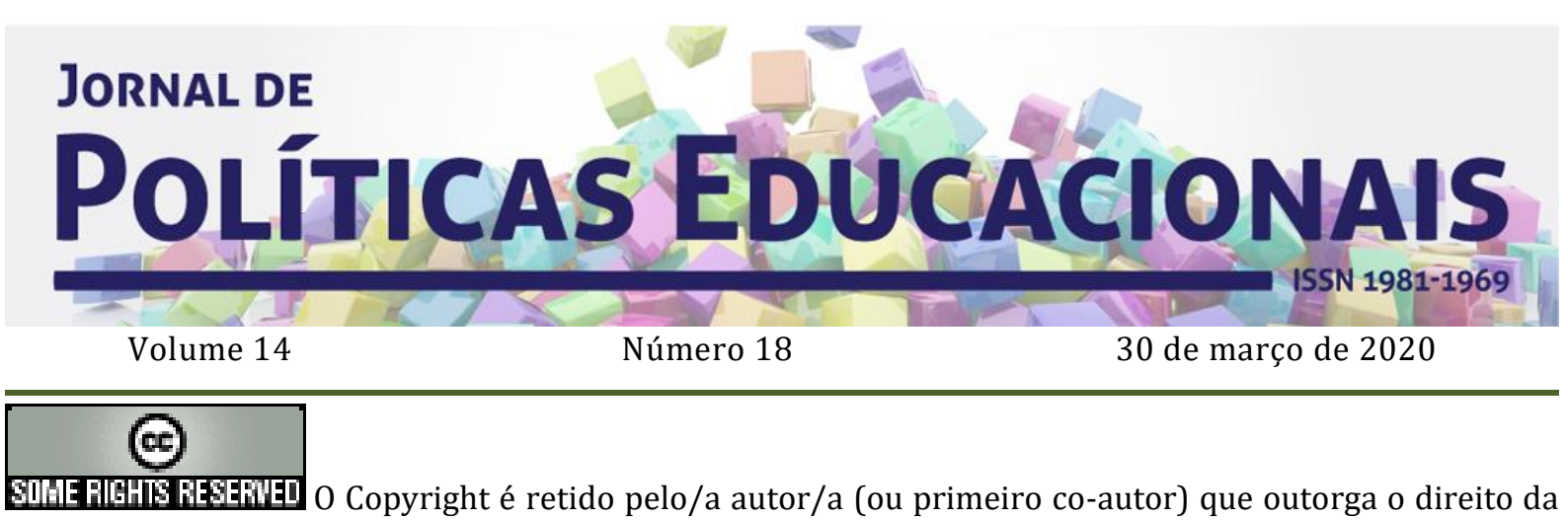

prime é retido pelo/a autor/a (ou primeiro co-autor) que outorga o direito da primeira publicação ao Jornal de Políticas Educacionais. Mais informação da licença de CreativeCommons encontram-se em http://creativecommons.org/licenses/by-nc-nd/2.5. Qualquer outro uso deve ser aprovado em conjunto pelo/s autor/es e pelo periódico.

JoRnAL DE Políticas EdUCACIONAIS é uma publicação do Núcleo de PolíticasEducacionaisdo Setor de Educação da Universidade Federal do Paraná - NuPE/UFPR, em consórcio com a Linha de Pesquisa em Políticas Educacionais do Programa de Pós-Graduação em Educação - PPGE/UFPR, que aceita colaboração, reservando-se o direito de publicar ou não o material espontaneamente enviado à redação. As colaborações devem ser enviadas ao NuPE/UFPR, conforme orientações contidas nas páginas do periódico na internet: http://revistas.ufpr.br/jpe.

\author{
Indexação: \\ BBE - Biblioteca Brasileira de Educação (MEC/INEP) \\ Clase (Base de Datos Bibliográfica de Revistas de Ciencias Sociales y Humanidades) \\ Diadorim - Diretório de Política de Acesso Aberto das Revistas Científicas Brasileiras (IBICT) \\ Google Scholar \\ Index Copernicus \\ Portal de Periódicos (CAPES) \\ SER - Sistema Eletrônico de Revistas da Universidade Federal do Paraná (SER/UFPR) \\ Sumários de Revistas Brasileiras (FUNPEC-RP) \\ DRJI - Directory of Research Journals Indexing
}

(Periódico integralmente disponível apenas em via eletrônica)

Jornal de Políticas Educacionais / Núcleo de Políticas Educacionais da Universidade Federal do Paraná NuPE/UFPR - v.1, n. 1 (1ํo semestre de 2007) - Curitiba: NuPE/UFPR.

Volume 14, número 18 - Março de 2020

ISSN 1981-1969

1. Educação - Periódicos. 2. Política Educacional - Periódicos. I. NuPE/UFPR

Comitê Editorial:

Elisângela Scaff (UFPR)

Daniela de Oliveira Pires (UFPR)

Conselho Editorial:

Andréa Barbosa Gouveia (UFPR - Brasil), Cesar Tello (Universidad Nacional Tres Febrero, Argentina), Fernanda Saforcada (Universidad de Buenos Aires - UBA - Argentina), Gladys Beatriz Barreyro (USP Brasil), Gustavo Enrique Fischman, (Arizona State University - USA), Jefferson Mainardes (UEPG - Brasil), João Ferreira de Oliveira (UFG - Brasil), Juca Gil (UFRGS - Brasil), Luiz Souza Júnior (UFPB - Brasil), Ney 
ALVARENGA, M.S.; SANTOS, C. Egressos da EJA no ensino superior e a política de cotas da UERJ: entre desafios e potencialidades

Cristina Monteiro de Oliveira (UFPA - Brasil), Nicolás Bentancur, (Universidad de la República de Uruguay), Robert Verhine (UFBA - Brasil), Rosana Cruz (UFPI - Brasil), Rubens Barbosa Camargo (USP - Brasil), Sebastián Donoso Díaz (Universidad de Talca - Chile), TheresaAdrião (UNICAMP - Brasil), Vera Peroni (UFRGS - Brasil).

Créditos e Agradecimentos:

Revisão de Língua Portuguesa, Abstract e Resumen: PROGRAMA DE APOIO ÀS PUBLICAÇÕES CIENTÍFICAS PERIÓDICAS DA UFPR

Arte e diagramação: TIAGO TAVARES (thiagotav@gmail.com)

Jornal de Políticas Educacionais

Universidade Federal do Paraná

Setor de Educação

Núcleo de Políticas Educacionais - NuPE/UFPR

Avenida Sete de Setembro, 2645

$2^{\circ}$ andar, Sala 213

80.230-010 - Curitiba - PR - Brasil

Tel.: 41-3535-6264

jpe@ufpr.br

http://revistas.ufpr.br/jpe 